\title{
Barriers and drivers in the adoption of advanced wastewater treatment technologies: a comparative analysis of Italian utilities
}

Paola Garrone, Luca Grilli, Angelamaria Groppi, Riccardo Marzano, Politecnico di Milano

\begin{abstract}
The adoption of new environmentally-friendly technologies is becoming a key issue in both public debate and policy arenas. The paper focuses on innovation adoption by wastewater utilities, and investigates why stringent environmental regulations are not sufficient to foster it. The adoption of advanced wastewater treatment technologies is made complex by the sunk nature of highly specific infrastructures, and the consequent exposure of utilities to political and institutional influences. In addition, it requires the involvement of various actors (utilities, suppliers, contractors), and is influenced by various stakeholders (communities, business users, citizens' associations) that generally have no aligned objectives.

With reference to the aforementioned theoretical background, our paper develops and analyzes a conceptual framework that unfolds over two dimensions: (a) the role played by firm-specific characteristics, i.e. technological and organizational capabilities and managerial professionalism; (b) the influence of community-level factors, i.e. citizens' voice and pressure exerted by local stakeholders.

We investigate these issues through multiple descriptive case studies based on semi-structured interviews with the CEOs and top managers of 11 wastewater utilities operating in a region in North-Italy. The results suggest that firm-specific resources could spur wastewater utilities into adopting innovation, despite an adverse institutional environment. At the same time, on the community-level side, the analysis shows that residents and local businesses are able to mobilize resources and exert pressure to either drive or hinder the adoption of water innovations.
\end{abstract}

\section{Keywords}

water innovation; wastewater; environment; adoption; infrastructure; utilities.

Resultant wordcount: 8,874 words 


\section{Introduction}

Water industries in advanced economies are evolving from a mere traditional hydraulicengineering logic to include more market-oriented and environmentally-friendly practices (Fuenfschilling and Truffer, 2014). The adoption of environmental innovations by water and wastewater utilities is clearly an important element in this transition path and, in principle, it should represent both a triggering cause and an ultimate outcome of the whole evolutionary dynamics. However, this paradigmatic shift is certainly not smooth. The obstacles to water innovation are numerous and still limitedly understood (Wehn and Montalvo 2014). First, the adoption decision regarding environmental technologies depends on a large number of determinants that are context-specific and interact mutually (Montalvo 2008). Secondly, the costs and rewards of sustainable innovation are distributed unevenly across the involved actors and communities (Boons et al. 2013). More specifically, environmental innovations in the water and wastewater industries have a pronounced systemic and infrastructural nature. Their deployment involves multiple and institutionally diverse stakeholders that express different interests, and may have conflicting objectives (Spiller and Savedoff 1999; EIP Water 2014). This multifaceted landscape introduces significant challenges for those who aim at easing the dynamic efficiency of the sector. The adoption of new environmental technologies in the water and wastewater industries is becoming a key issue in public debate and policy arenas (EC 2013a; EIP Water 2014; OECD 2011a, 2011b, 2012).

This paper addresses the factors that are behind the decision of a few Italian wastewater utilities to adopt Advanced WasteWater Treatment (AWWT) technologies, although a part of the industry resisted their adoption, despite supposedly stringent water quality standards. ${ }^{1}$ The AWWT case represents a special yet interesting instance of environmental innovation adoption. ${ }^{2}$ It allows us to shed light on an under-explored issue, that is, the diffusion of environmental technologies in the water sector and more generally in all the infrastructural sectors that are subject to institutional and political pressures. In doing so, we offer insights into why standards and other command-andcontrol regulations could have less power than expected and may represent weak drivers toward

\footnotetext{
${ }^{1}$ AWWT technologies hereafter refer to so-called "Tertiary" technologies that treat excess nutrients (see Section 2.1).

${ }^{2}$ In this paper, the "environmental innovation" label has been used to term the new wastewater treatment systems, which are quintessential End-of-Pipe technologies (OECD 2011a).
} 
the adoption of environmental process innovations. In this respect, the possible ways of how to complement these mechanisms are also discussed.

In principle, AWWT adoption is not at the discretion of the utilities. The European standards on water quality (Council Directive 91/271/EEC) were aimed not only at conserving the environment, but also at safeguarding people from contamination risks from poorly treated wastewater (OECD 2011a). Nevertheless, the adoption of AWWT technologies is made complex by the presence of several intrinsic factors, as documented by the infringement cases that have been opened up against several European Union (EU) Member States (MSs) (EC 2013b). The barriers met by utilities may differ from those met by manufacturers (Luken and Van Rompaey 2008). First, the new assets are specific to the local geography, economy and society, and the AWWT have to be "fine-tuned" to the target hydrological context (Spiller and Savedoff 1999; EC 2013a). Transaction cost economics suggests that asset specificity implies substantial sunk costs, an event that in regulated utilities opens the way toward governmental opportunism (Williamson 1976; Spiller 2013). Interaction with local governments and sector regulatory authorities is a distinctive trait of most water process innovations. Water resources management is an inherently political process, whose hazards have not been recognized sufficiently in the environmental literature (Mollinga 2008, Spiller 2013). Second, this process innovation has to be adapted to the existing infrastructural capital and production processes (Delmas et al. 2007; Montalvo 2008). Third, as pointed out in the literature on socio-technical systems and environmental innovation (Boons et al. 2013), the internal and external stakeholders of wastewater utilities are numerous and diverse, i.e. public and private owners, managers, employees, suppliers, customers, local water using vs. polluting industries, citizens and politicians of the local community, as well as residents of downstream cities and regions. The benefits and costs related to the adoption of AWWT technologies accrue in different proportions to these players (Mitchell et al. 1997; Khanna and Damon 1999; Harvey and Schaefer 2001; Buysse and Verbeke 2003; Montalvo 2008).

A number of interesting challenges for legislators, regulators and managers arise from these particular characteristics. Firstly, AWWT adoption takes place in a regulated context, in which the utilities are obliged to comply with specific urban quality standards, but infrastructural investments may be reduced by the risk of governmental opportunism. Despite environmental regulation, utilities may end up underinvesting in auspicious AWWT technologies simply because the regulators cannot credibly commit themselves to reward investment overtime adequately. Secondly, the deployment of AWWT technologies requires the involvement of various actors 
within the value-chain network. Utilities, suppliers and contractors have to possess adequate technological and organizational capabilities. An even more difficult obstacle to overcome is the lack of professionalism of those utility managers whose careers depend on connections with local politics more than on job markets. Thirdly, a large number of stakeholders, who do not necessarily have aligned objectives, can influence adoption choices. The composition of all these interests is far from obvious.

The extant literature has generally provided a macro-perspective on water innovation issues (Krozer et al. 2010; Wehn and Montalvo 2014), but there is still a lack of micro-level evidence on the forces that drive AWWT investments. Considering the preexisting studies on the adoption of environmental technology (Montalvo, 2008), transaction costs in regulated industries (Spiller 1993; Spiller 2013), institutional pressures, innovation systems and environmental management (Khanna and Damon 1999; Buysse and Verbeke 2003; Boons et al. 2013; Berrone et al. 2013), our paper develops and analyzes a conceptual framework that explains whether and how utilities adopt new AWWT technologies. The framework unfolds along two major dimensions, and identifies four main conceptual drivers of the adoption of AWWT technologies by utilities: (a) firmlevel factors: utility endowment, in terms of technological and organizational capabilities and managerial professionalism; (b) community-level factors: the strength of the citizens' voice and local business vocation in terms of water usage.

This interpretative framework is sustained and corroborated through descriptive multiple case studies. The analysis focuses on utilities located in a region in North-Italy (about 7 million served inhabitants), with a balanced proportion of adopting and non-adopting utilities.

The remainder of this paper is organized as follows. Section 2 describes AWWT technologies in more detail and provides an overview of the wastewater treatment sector in the specific geographical context analyzed here. Sections 3 and 4 review the relevant literature and depict the conceptual background of the analysis, respectively. Section 5 describes the methodology and the nature of the information collected through the case studies. Section 6 illustrates the results and discusses the main findings in light of the conceptual framework. Finally, Section 7 draws up the theoretical and practical implications of the findings. 


\section{Wastewater treatment: technologies and regulations}

\subsection{Technology overview}

Wastewater treatment technologies can be classified into four stages. The Preliminary Stage refers to simple tasks, such as the grit and gravel removal of gross solid pollution. The Primary Stage has the aim of settling large suspended matter, by means of physical or chemical processes. The Secondary Stage reduces organic matter, usually by means of a biological process. Finally, the Tertiary Stage treatment deals with different pollutants (e.g. nitrogen and phosphorous, or specific industrial pollutants), and takes on a variety of forms, such as ultra-violet light irradiation, microfiltration or chemical dosing.

In this paper, AWWT technologies are defined as Tertiary Stage treatment processes that protect water from eutrophication by reducing excess nutrients, i.e. phosphorus and nitrogen compounds, as established by European regulations for "sensitive areas", such as the Italian region dealt with in this case study. Water areas in need of greater protection are designated as 'sensitive areas', according to the Council Directive 91/271/EEC, which regulates urban wastewater (UWW) treatment. In general, various AWWT technologies exist, but they all pose relatively similar engineering and economic challenges, apart from the "fine tuning" efforts that are necessary to adapt a technology to a specific WWT plant. A denitrification stage is installed before, inside or after the secondary biological reactor, while a dedicated coagulation-flocculation stage serves the purpose of removing phosphorous, except for in smaller WWT plants, which add a chemical precipitation component to the secondary treatment stage.

\subsection{European Union Regulations}

Council Directive 91/271/EEC was adopted with the aim of properly managing UWW and protecting receiving surface waters and the aquatic environment in EU MSs. In other words, the Directive requires the collection and treatment of wastewater in all agglomerations of $>2,000$ population equivalents (p.e.), the secondary treatment of all discharges from agglomerations of $>2,000$ p.e., and the introduction of AWWT for agglomerations $>10,000$ p.e. in designated sensitive areas. The implementation programme introduced sequential key milestones, with the last deadline expiring at the end of 2005 for EU-15 MSs, but their implementation still presents significant challenges (EC 2013b). 


\subsection{Institutional setting for wastewater technologies in Italy}

Italy adopted Council Directive 91/271/EEC in 1999, even though transposition was due by 1993. Nevertheless, the AWWT investment gap has not been closed since then, mainly as a consequence of industry fragmentation, weak institutions and exceedingly low tariffs (Federutility 2014).

Traditionally, water distribution, sewerage and wastewater treatment services are highly fragmented in Italy, and in-house municipally-owned providers prevail. The so-called "Galli reform" of 1994 (Law 36/1994), aimed at integrating water and wastewater services, had the purpose of enabling economies of scale through mergers of utilities and of covering costs through tariffs (Romano et al. 2015). In addition, regions were delegated to identify "optimal" water districts, to be operated by a single integrated water and wastewater utility, whose tariff would be increased and investment plans would be monitored and approved by a local regulator (currently there are 71 water districts). However, after more than 20 years, the "Galli Law" has remained largely unaccomplished. In 2012, there were 3,161 water and wastewater providers; most of which were in-house suppliers (2,617) (ISTAT 2015). Environmental management capabilities are jeopardized by fragmentation, as testified, for instance, by the uneven diffusion of Environmental Management Systems (such as ISO 9001, ISO 14001, ISO 50001). ${ }^{3}$ Secondly, conflicts of interests have plagued the Municipalities, most of which are utility shareholders, participate in the local regulator boards, and, as politicians, may seek voters' support (through low tariffs and in some cases patronage practices). Thirdly, the tariffs did not implement the "Full Cost Recovery" rule and were lower than the mean OECD tariffs (OECD 2013; AEEGSI 2012); at the same time, they relied on planned rather than executed investments (Romano et al. 2015). In 2011, a Referendum restored in-house provision, which had been banned in 2009 (Law 166/2009), and curbed investment remuneration. Only in 2012 were economic regulation tasks assigned to an independent Regulatory Authority, i.e. the traditional energy regulator.

In 2012, there were 18,162 wastewater treatment plants running in Italy (ISTAT, 2014), but only $10 \%$ of the plants featured AWWT technologies. However, these plants treated $60 \%$ of the collected pollution load; Secondary Stage plants treated 35\%, while the remaining facilities $(10,226$ small-sized plants) treated the remaining $5 \%$.

\footnotetext{
${ }^{3}$ According to a recent ISO Survey on Certification (2015), only 650 and 272 Italian firms belonging to a generic "water supply" sector were ISO 9001 and ISO 140001 certified, respectively, in 2014. For more details, the reader can refer to http://www.iso.org/iso/iso-survey.
} 
The compliance rates of MSs with Council Directive 91/271/EEC are shown in Table 1 . All the deadlines had expired by 31 December 2005, but Italy is still far from having complied fully. Since 1997, the European Commission has opened a number of infringement procedures, and Italy has been sanctioned twice, under procedures no. 2004/2034 and no. 2009/2034 (Court judgements C$565 / 10,2012$, and C-85/1, 2014, respectively). The second procedure is specifically relevant for the present analysis: Italy was found guilty of not having met its AWWT obligations in 41 agglomerations (>10,000 p.e.) and of discharging into receiving waters considered as sensitive areas (see Section 2.1 for a definition). A third procedure is still in progress (ISTAT, 2015).

\begin{tabular}{|l|r|r|r|}
\hline \multicolumn{1}{|c|}{$\begin{array}{c}\text { EU-15 Member } \\
\text { State }\end{array}$} & $\begin{array}{c}\text { Collection compliance } \\
\text { rate (\%) }\end{array}$ & $\begin{array}{c}\text { Secondary treatment } \\
\text { compliance rate (\%) }\end{array}$ & $\begin{array}{c}\text { AWWT compliance } \\
\text { rate (\%) }\end{array}$ \\
\hline Austria & 100 & 100 & 100 \\
\hline Belgium & 78 & 73 & 52 \\
\hline Denmark & 100 & 99 & 94 \\
\hline Finland & 100 & 97 & 97 \\
\hline France & 96 & 84 & 87 \\
\hline Germany & 100 & 100 & 100 \\
\hline Greece & 100 & 99 & 100 \\
\hline Ireland & 100 & 40 & 2 \\
\hline Italy & $\mathbf{8 7}$ & $\mathbf{6 4}$ & $\mathbf{8 6}$ \\
\hline Luxembourg & 100 & 57 & 38 \\
\hline The Netherlands & 100 & 100 & 100 \\
\hline Portugal & 97 & 47 & 20 \\
\hline Spain & 98 & 86 & 54 \\
\hline Sweden & 100 & 99 & 87 \\
\hline The United Kingdom & 100 & 98 & 63 \\
\hline EU-15 average & $\mathbf{9 7}$ & $\mathbf{8 8}$ & $\mathbf{9 0}$ \\
\hline
\end{tabular}

Table 1. Compliance rate of EU-15 Member States with Council Directive 91/271/EEC. Source: $7^{\text {th }}$ Implementation Report (EC 2013b)

\subsection{AWWT adopters v. non-adopters}

In this paper, the examined region in North-Italy is classified as a "sensitive area"; 21 agglomerations located in 6 out of the 13 extant water districts were judged as not having complied with Council Directive 91/271/EEC. A utility is defined "non-adopter" if at least one of the served agglomerations does not comply with the Directive because the utility failed to adopt AWWT technologies (see the definition in Section 2.1); the other wastewater utilities are termed "adopters". 


\section{Literature review}

This Section reviews the determinants of AWWT adoption. The adoption of environmental innovations can be expected to occur under the conditions surveyed by Montalvo (2008). At the same time, it should be recalled that the adopting utilities have to deploy or modernize infrastructural facilities; thus they bear those transaction costs that institutional economists, from Williamson (1976) and Goldberg (1976) onwards, have attributed to asset specificity and governmental opportunism in the presence of a weak institutional framework. Moreover, wastewater utilities have to deal with numerous stakeholders who exert different forms of pressure. Institutional economics, the literature on innovation systems and stakeholder theories offer a lens to identify these groups and to gauge their interest in the environmental management of utilities (Mitchell et al. 1997; Khanna and Damon 1999; Buysse and Verbeke 2003; Boons et al. 2013; Berrone et al. 2013). Finally, this review also cites some results from a contiguous field, namely technology diffusion. ${ }^{4}$

The remaining part of this Section summarizes industry-, community- and firm-level factors that may act as barriers to or drivers of the adoption of AWWT technology.

Environmental and sector policies are the main instances of industry-level adoption determinants. The standards described in Section 2.2 are command-and-control environmental policies, which may be supposed to ensure the adoption of end-of-pipe discharge reduction technologies, because firms want to pre-empt stricter future regulations (Montalvo 2008). However, firms attach mixed or weak importance to environmental regulators (Buysse and Verbeke, 2003; Kassinis and Vafeas, 2006). The economic regulation of wastewater monopolies may act as a second industry-level barrier to their adoption. Any economic decision in infrastructural sectors takes place within a complex structure of interactions between governments and the utilities themselves. National regulators, on the one hand, and local residents and industries, on the other, are critical components of the AWWT innovation system (Boons et al. 2013; Lopez and Montalvo 2015). Appropriation of returns is a source of uncertainty for any innovation, but transaction cost

\footnotetext{
${ }^{4}$ An analysis of the diffusion of AWWT technologies would allow the issue of wastewater sector sustainability to be tackled comprehensively, but this would involve going beyond the current stage of research. Diffusion patterns at the population level can only be studied if the industry is observed over time and if significant changing stimuli occur (Kemp and Volpi 2008). However, the Italian wastewater industry has only very recently experienced such stimuli, through the establishment of an independent national regulatory authority, and through a clear implementation of a full cost recovery principle in tariffs.
} 
economics shows that regulated utilities suffer from even harsher economic hazards (Williamson 1976; Goldberg 1976; Spiller 1993; Spiller and Savedoff 1999; Spiller 2013).

The underinvestment risk is sizeable in utility sectors, due to the technological and geographic specificity of assets and so-called governmental opportunism (Spiller 1993). Governmental opportunism hails from the government's power to change rules, and may be exerted toward State-owned or private utilities (Spiller and Savedoff 1999). Since a large component of investments is sunk, once the utility has made the investment, governments may extract the investment quasi-rents in harsh or subtle ways, namely by denying a tariff increase, exercising discretion in regulatory supervision, or modifying franchising rules (Spiller 2013). Governments pay limited political costs to change rules, because the sunk investment implies that the utility will be willing to keep operating even if the tariffs are lowered below the average costs or reviews are postponed. The benefits for politicians who seek voters' support, and know that their constituencies care above all about utility pricing may instead be large (Levy and Spiller 1994; Spiller and Savedoff 1999; Spiller 2013). Governmental opportunism thrives in countries that are institutionally weaker (e.g. no tradition of regulator independence; Spiller 1993; Levy and Spiller 1994). In conclusion, governmental opportunism under a weak governance framework is expected to discourage utilities from adopting new AWWT technologies.

Industry-level policies explain why wastewater industries may experience a gap in the adoption of new AWWT technologies, but community- and firm-level dimensions are necessary to understand intra-industry adoption choices.

Among the community-level determinants, the attitude of residents and local industrial users toward environment protection drives the wastewater utility to adopt or not to adopt AWWT technologies. Firstly, a greater willingness of customers to pay for a cleaner product encourages the firm to innovate its processes (Montalvo 2008). Demand pull from customers has been found to be a significant driver for firms that adopt environmentally-friendly innovations (Veugelers 2012). Secondly, citizens and local industries are also local stakeholders, whose pressures may promote environment and health protection through various channels, from individual activism to consumer groups and NGO activity (Montalvo 2008). Firms introduce pollution control innovation to gain public recognition and legitimacy (Khanna and Damon 1999). However, the empirical findings on the role of various stakeholders are still mixed (Buysse and Verbeke 2003; Montalvo 2008; Berrone et al. 2013). The composition of interests is not obvious. Managers pay attention to 
the stakeholders as long as the latter show a high degree of legitimacy and power, and to the extent that they convey urgent demands (Mitchell et al. 1997). Concerns about poor environmental performances could be raised vaguely by citizens, whereas the same individuals could be much more concerned as customers (Harvey and Schaefer 2001).

The characteristics of a firm are also deemed to explain environmental innovating activities. The probit approach to diffusion studies emphasizes that different patterns of innovation diffusion arise from user heterogeneity (Karshenas and Stoneman 1993). Management quality and organizational capabilities lead firms to progress more rapidly in the adoption of environmental technologies (Bloom et al. 2010; Martin et al. 2012). Professionalism and a leadership attitude of the CEO and other top managers are necessary to convince shareholders, engage with suppliers, and to lead to operational changes within the company (Montalvo 2008). Technological capabilities represent another critical element. The presence of regulatory obligations makes information transfer quite easy, but the ability to process information on "how to use technology" requires sufficient capabilities at the firm-level (Geroski 2000). Insufficient expertise and understanding of environmentally-friendly production may hamper the adoption of new cleaner processes (Montalvo 2008). In short, the cost of absorbing the technology within a firm's production processes and the ultimately efficient usage of the wastewater innovation depend to a great extent on the technological and organizational know-how of the utilities (Delmas et al. 2007; Montalvo 2008). Finally, most firm-level barriers to adoption are expected to be even harsher in smaller enterprises (Montalvo 2008).

\section{Conceptual Framework}

The standards in force for urban water quality should have led Italian wastewater utilities to adopt AWWT technologies virtually without exception. However, AWWT technologies are highly specific to the community for which they are designed: they have to ensure given treatment functions, to meet the local demands (in terms of wastewater sources, flows and emissions), and to adapt to the hydrological characteristics of the site. Sunk investments create the potential for governmental opportunism in any wastewater industry, even more so in the Italian one, owing to its traditional weak institutional background (before 2012, when an independent national regulator was established; Section 2.3). Local governments had a great deal of influence on tariffs, a politically sensitive issue, since they appointed members of the local regulators and in most 
cases owned the utilities. Franchising rules and service contracts were other obvious areas of influence. On the basis of the adverse consequences of governmental opportunism, one might easily conclude that Italian wastewater utilities present an intrinsic reluctance to adopt AWWT technologies. However, as seen in Section 2.4, the picture is more scattered, namely there are both adopting and non-adopting utilities.

Our contribution deals with four micro-level forces that may influence AWWT adoption, despite urban water quality policies, or may spur it, despite governmental opportunism. Two of these drivers refer to utility characteristics, i.e. "technological \& organizational capabilities" and "management professionalism". The other two, "citizens' voice" and "water using / polluting industries" pertain to the geographical and social context on which the utilities operate. A graphical representation of the conceptual framework is depicted in Figure 1.

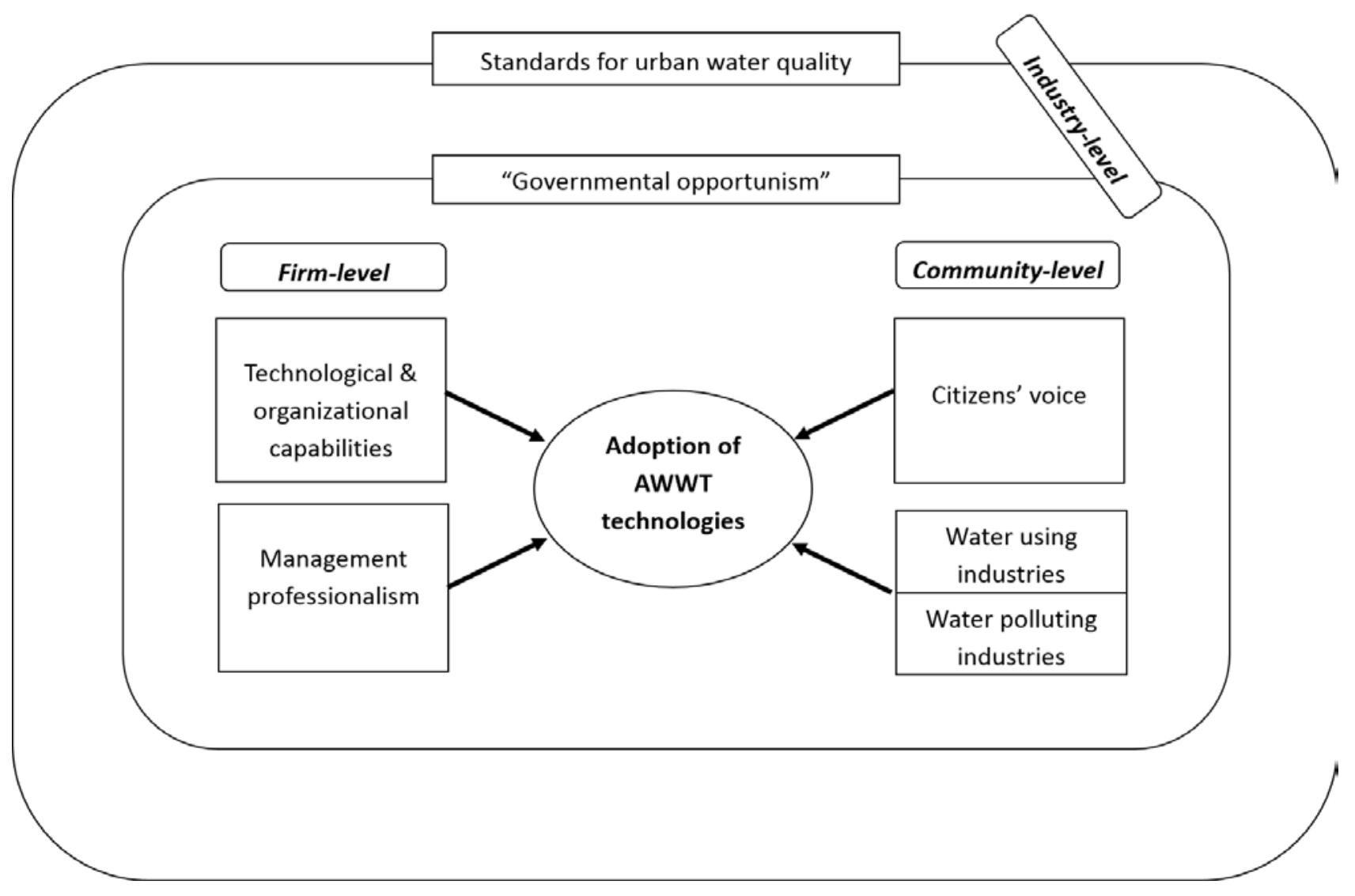

Figure 1. Adoption of AWWT technologies: the conceptual framework

The Italian wastewater sector is characterized by a great heterogeneity, in terms of endowment of technological \& organizational capabilities, due to the lack of any form of competition acting as a selection mechanism. As discussed in Section 3, these capabilities are deemed to discriminate 
between adopters and non-adopters, which may differ in terms of cumulated knowledge capital, as well as expertise and know-how about environmental and community-specific issues. The deployment of AWWT technologies entails considerable potential absorption costs because of the unavailability of off-the-shelf solutions and the need of fine-tuning according to the geographical and societal context. Utilities characterized by lower potential absorption costs, i.e. the most endowed utilities in terms of technological \& organizational capabilities, have relatively higher, ceteris paribus, incentives to adopt the technology, because the relative future costs for standard infringements could be perceived as being higher than the present adoption costs. For the same reasons, it could be expected that those utilities that are less endowed with technological \& organizational capabilities are less inclined to adopt in the short term.

The second utility-specific factor is management professionalism, a critical feature of the diversified landscape of the Italian wastewater industry (see Section 2.3). There are professional managers who run medium- or large-sized utilities in a businesslike manner, and who perceive themselves as being on the market for managerial jobs. At the same time, public managers of small and medium-sized utilities are likely to experience less pronounced career concerns (a sideeffect of water service fragmentation coupled with in-house delivery). They might share an agenda scattered by political considerations with local politicians. We claim that professional managers are eager to build their reputation on the manager market and are willing to innovate to a greater extent than their "internal-career" counterparts.

As far as the community side is concerned, this paper embraces a comprehensive perspective. In this respect, the relative salience of stakeholders, as perceived by managers in each territory, is the key factor. Managers are well aware that local communities have multifaceted priorities with respect to wastewater operations, owing to the simultaneous presence of the general public, the owners and employees of local companies, water utility employees, and customers. The composition of these very different interests is not obvious, and depends on the managers' perceptions of the stakeholders (see Section 3).

The noxious impacts of poorly treated wastewater can be perceived differently, depending on the extant pollution burdens or hydrological conditions (e.g. dry water bodies make the noxious effect of releases more visible). Individual citizens and/or groups in more anthropic territories may voice their interest, and demand water companies to adopt AWWT technologies to protect their health and the environment. Besides this, however, business pressure groups are seen as legitimate and 
powerful holders of urgent and well-specified needs. Local communities may derive a significant part of their income from local industries that release polluting effluents, e.g. from chemical manufacturing or textile dyeing. In this case, industrial users will oppose adoption, for instance by claiming that the tariffs entail a disproportionately large part of the AWWT costs. Individual citizens, trade unions and political parties will join in on the debate on the grounds that profitability reduction is a threat to local community employment and welfare. On the other hand, some communities rely to a great extent on a clean environment and high quality water. Local industries whose operations critically depend on the quality of drinking water or surface water bodies, e.g. recreational activities and tourism, are willing to pay for a high water quality, and to encourage adoption. Citizenship, NGOs and most political parties will also support AWWT adoption, because water quality is a specific territorial asset and a source of competitive advantage for the whole community.

\section{Sample and methodology}

The empirical research has dealt with multiple case studies. The unit of analysis is the wastewater utility, and the focus is on the choice to adopt or not adopt AWWT technologies.

The sample includes 11 utilities from one single, large region in North-Italy. A single-region study has made it possible to reduce the possible impact of unobserved differences in regional regulations and politics. At the same time, the size of the region entails a significant variance across utilities and communities, a fact that has made it possible to perform a meaningful comparison of cases. The cases were selected according to the following main criteria: coverage of as many of the 13 regional water districts in the region as possible; a balance between innovation adopters and non-adopters; the inclusion of districts that host both water using and water polluting industries. The utility's status, in terms of AWWT adoption, is based upon objective information, as discussed in Section $2.4 .{ }^{5}$ We found that five out of the 11 investigated cases have infringed the EU standards on UWW treatment. ${ }^{6}$

\footnotetext{
${ }^{5}$ Since the information on the adopting behavior has not been drawn from the same sources as those from which the data for the explanatory variables were obtained, the so called "common method bias" is unlikely to represent a concern in our empirical setting (Chang et al., 2010).

6 As pointed out by an anonymous reviewer, AWWT technologies could have different costs and technical requirements, which may influence the comparison between cases. However, as already mentioned in Section 2.1, we focused on AWWT technologies that have the aim of reducing phosphorous and nitrogen compounds, thus the variety of AWWT technologies at stake has been decreased; affordable options are available for smaller WWT plants.
} 
Table 2 summarizes the main characteristics of the 11 sample cases. Wastewater utilities $E$ and $H$ belong to multi-utility groups. Six out of the 11 sample utilities are fully owned by the local municipalities; utilities $B$ and $E$ are partially privatized; only utilities $D$ and $F$ are controlled by private owners. Eight firms are joint ventures owned by a large number of municipalities, which is a prevalent pattern in Italy. Finally, 2 utilities are large (revenues greater than 100 million Euros), 5 utilities are middle-sized (between 20 and 65 million Euros) while the remaining 4 utilities are smaller.

\begin{tabular}{|c|c|c|c|c|}
\hline $\begin{array}{l}\text { Wastewater } \\
\text { utility }\end{array}$ & $\begin{array}{l}\text { Multi- } \\
\text { utility }\end{array}$ & $\begin{array}{l}\text { Ownership and Governance } \\
\text { (Number of Municipalities) }\end{array}$ & $\begin{array}{l}\text { Revenues } \\
\text { [million } € \text { ] }\end{array}$ & $\begin{array}{l}\text { Served } \\
\text { inhabitants }\end{array}$ \\
\hline \multicolumn{5}{|l|}{ Adopters } \\
\hline A & NO & $\begin{array}{l}\text { 100\% municipal } \\
\text { (1 Municipality) }\end{array}$ & 120 & $2,000,000$ \\
\hline B & NO & $\begin{array}{l}\text { 20\% private, } 80 \% \text { municipal } \\
\text { (18 Municipalities) }\end{array}$ & 13 & 97,000 \\
\hline$C$ & NO & $\begin{array}{c}\text { 100\% municipal } \\
\text { (116 Municipalities) }\end{array}$ & 40 & 370,000 \\
\hline $\mathrm{D}$ & NO & $\begin{array}{l}\text { 99\% private, } 1 \% \text { municipal } \\
\text { (3 Municipalities) }\end{array}$ & 5 & 42,000 \\
\hline$E$ & YES & $\begin{array}{c}40 \% \text { private, } 60 \% \text { municipal } \\
\text { (70 Municipalities) }\end{array}$ & 23 & 220,000 \\
\hline $\mathrm{F}$ & NO & $\begin{array}{c}\text { 65\% private, } 35 \% \text { municipal } \\
\text { (4 Municipalities) }\end{array}$ & 6 & 104,000 \\
\hline \multicolumn{5}{|l|}{ Non-Adopters } \\
\hline G & NO & $\begin{array}{c}\text { 100\% municipal } \\
\text { (189 Municipalities) }\end{array}$ & 60 & 530,000 \\
\hline $\mathrm{H}$ & YES & $\begin{array}{c}\text { 100\% municipal } \\
\text { (87 Municipalities) }\end{array}$ & 40 & 300,000 \\
\hline 1 & NO & $\begin{array}{c}\text { 100\% municipal } \\
\text { (197 Municipalities) }\end{array}$ & 230 & $1,900,000$ \\
\hline $\mathrm{J}$ & NO & $\begin{array}{c}\text { 100\% municipal } \\
\text { (55 Municipalities) }\end{array}$ & 65 & $1,000,000$ \\
\hline K & NO & $\begin{array}{l}\text { 60\% three water utilities, } 40 \% \text { municipal } \\
\text { (123 Municipalities) }\end{array}$ & 18 & 700,000 \\
\hline
\end{tabular}

Table 2. Sample description

We decided for descriptive case studies that suit the purpose of the present research, namely, the expansion and adaptation of existing theories on the adoption of environmental innovations pertaining to the case of infrastructural sectors such as water. Descriptive case studies allowed us to understand how individual factors unfold in the context at stake and to discover how they combine to determine the AWWT adoption choice. 
The case studies followed a comprehensive protocol, which allowed the particular internal features of various districts (community-level factors) and the utility characteristics that explain their technological and organizational capabilities and management professionalism (firm-level factors) to be studied in depth. Researchers visited the utility venues and conducted detailed faceto-face interviews for at least 2 hours with the CEO and/or technical or operations manager (for a total of 18 interviewees), as can be seen in Table 3. The researchers recorded, transcribed and coded the collected information. The different sections of the semi-structured interview protocol reflected the conceptual framework (see Section 4): general information, managerial professionalism and corporate governance, technological and organizational capabilities, citizens' voice and the socio-economic characteristics of districts. The information on firm-specific drivers was mainly collected through the interviews. The presence and perceived significance of the following antecedents of technological and organizational capabilities, and of managerial professionalism were investigated: Environmental Management Systems (Wagner, 2008), internal engineering office, top management recruitment and careers. The interviews also touched on the influence of internal and external stakeholders on investment planning decisions. General information on the utilities and communities was mainly collected from secondary sources: official documents and reports, Chambers of Commerce, news from websites, media, as well as national and regional statistics. The collected data concern the utility size (revenues, employees, served inhabitants), service mix and ownership (municipalities, local private shareholders, domestic and foreign utilities) and the presence of water polluting or water using industries (e.g. textile or chemicals, tourism and recreational services or water and food industries) in the served communities.

The data were collected from July 2014 to June 2015. In eliciting responses, it was specified that we were interested in utilities and communities for the 1999-2009 period, that is, from the adoption of the focal Directive to the opening of the infringement procedure. The same approach was used throughout the secondary data collection phase.

\begin{tabular}{|c|c|}
\hline Wastewater utility & Interviewee's role (No.) \\
\hline A & Technical Manager (1) \\
\hline B & CEO (1) - Technical Manager (1) \\
\hline C & CEO (1) - Technical Managers (2) \\
\hline D & Technical Manager (1) \\
\hline E & Technical Manager (1) \\
\hline F & Technical Manager (1) \\
\hline G & CEO (1) \\
\hline
\end{tabular}




\begin{tabular}{|c|c|}
\hline $\mathrm{H}$ & CEO (1) \\
\hline $\mathrm{I}$ & Technical Managers (2) \\
\hline $\mathrm{J}$ & Technical Manager (1) \\
\hline $\mathrm{K}$ & CEO (1) - Technical Managers (2) - Marketing Manager (1) \\
\hline Total & $\mathbf{( 1 8 )}$ \\
\hline
\end{tabular}

Table 3. Interviews with utilities

The utility case studies were triangulated with face-to-face interviews with 18 technology and service providers and local regulators (for a total of 24 interviewees), as illustrated in Table 4 . The interviews with third parties converged on the same topics as those of the utilities, in order to control and enrich the views expressed by the utility managers. The interviews with the water district regulators were focused on the authorities that monitored the tariffs and investment plans for utilities A, C, G and K, in order to obtain their views and comments on more uncertain subjects, such as investment priorities and the influence of district-specific characteristics.

\begin{tabular}{|l|l|c|c|}
\hline \multicolumn{2}{|c|}{ Actor } & $\begin{array}{l}\text { Number of } \\
\text { Interviews }\end{array}$ & Interviewee's role (No) \\
\hline $\begin{array}{l}\text { Technology } \\
\text { providers }\end{array}$ & Systems & 4 & $\begin{array}{c}\text { Sales Managers (4) - Technical Managers (2) - } \\
\text { Marketing Manager (1) }\end{array}$ \\
\cline { 2 - 4 } & Components & 3 & Sales Managers (3) - Technical Manager (1) \\
\hline Engineering \& Contracting & 4 & Sales Managers (3) - Technical Managers (2) \\
\hline Service providers & 3 & Sales Managers (3) \\
\hline \multicolumn{2}{|r|}{ Local regulatory authorities } & 4 & General Managers (3) - Technical Managers (2) \\
\hline \multicolumn{2}{|r|}{ Total } & $\mathbf{1 8}$ & (24) \\
\hline
\end{tabular}

Table 4. Triangulation interviews with third parties

\section{Results and discussion}

The results of our analysis are summarized in Table 5, which reports the intensity of the four main factors that drive AWWT adoption for each utility sample (see Figure 1). For the sake of brevity, a 3-grade ordinal scale has been used; the intensity of each determinant has been rated Low, Medium or High. The interviews with the utilities and third parties and the analysis of secondary sources obviously yielded more complex and richer information. Thus, the remaining part of this Section explains what the antecedents and components of the four main drivers are in detail, and discusses the main implications of the obtained results in terms of corroboration of the conceptual framework.

\begin{tabular}{|l|c|c|c|c|c|}
\hline \multirow{2}{*}{$\begin{array}{l}\text { Wastewater } \\
\text { utility }\end{array}$} & \multicolumn{2}{|c|}{ Firm-level drivers } & \multicolumn{3}{c|}{ Community-level drivers } \\
\cline { 2 - 5 } & $\begin{array}{c}\text { Technological \& } \\
\text { organizational } \\
\text { capabilities }\end{array}$ & $\begin{array}{c}\text { Management } \\
\text { professionalism }\end{array}$ & $\begin{array}{c}\text { Citizens' } \\
\text { voice }\end{array}$ & $\begin{array}{c}\text { Water using } \\
\text { industries }\end{array}$ & $\begin{array}{c}\text { Water } \\
\text { polluting } \\
\text { industries }\end{array}$ \\
\hline
\end{tabular}




\begin{tabular}{|c|c|c|c|c|c|}
\hline \multirow{2}{*}{\multicolumn{6}{|c|}{ Adopters }} \\
\hline & & & & & \\
\hline A & High & High & Medium & Medium & Low \\
\hline B & High & High & Medium & Medium & Medium \\
\hline $\mathrm{C}$ & High & Medium & Medium & Medium & Medium \\
\hline D & High & High & High & High & High \\
\hline$E$ & High & Medium & Medium & Medium & Medium \\
\hline $\mathrm{F}$ & High & High & High & High & High \\
\hline \multicolumn{6}{|c|}{ Non-Adopters } \\
\hline G & Medium & Medium & Medium & Medium & Medium \\
\hline $\mathrm{H}$ & Medium & Low & Medium & Medium & High \\
\hline 1 & Medium & Low & Medium & Medium & Medium \\
\hline$J$ & Low & Low & Medium & Medium & High \\
\hline $\mathrm{K}$ & Low & Low & Medium & Medium & High \\
\hline
\end{tabular}

Table 5. Summary of the findings of the case studies

\subsection{Firm-level determinants: Technological and organizational capabilities}

Antecedents of technological and organizational capabilities are present with varying intensities and varying combinations in the sample utilities, but they are concentrated in the adopters. The case studies have revealed that the development of critical capabilities for AWWT adoption was mainly driven by the accumulation of advanced technological knowledge, learning and know-how about environmental issues, as documented by the certifications, business relationships and alliances with engineering and industrial companies. The learning economies associated to experience in the focal activities were also found to play a major role, while size effects have less importance. $^{7}$

- Knowledge capital. Utility A maintains steady relationships with research centers, wins competitive grants to carry out innovative technological projects, and is an active member of the International Water Association. Utility $\mathrm{C}$ benefits from participation in a network of smallmedium sized utilities. This alliance fosters technological and organizational learning through knowledge transfer and the exchange of best practices, but also because the partner utilities are monopolists of other districts and not rivals (Ford et al., 2014). The innovation potential of Utility $C$ leans on cooperation with one university and the presence of an internal certified laboratory for water quality tests. Cases $D$ and $E$ take part in innovative technological projects and cooperate with research centers. Instead, neither participation in research projects or

\footnotetext{
${ }^{7}$ For the sake of exposition, the reported facts are generally presented using the present tense but they always do refer to the 1999-2009 period.
} 
steady links with research centers have been reported for the remaining (non-adopting) utilities. The technology providers have confirmed that most of the non-adopters are technology laggards.

- Environmental know-how. According to the interviewed technology providers, the adoption of Environmental Management Systems (EMSs) is a privileged mechanism that is adopted to reinforce staff competencies, for instance through training, and to measure performances. ${ }^{8}$ Utilities D and F are ISO 9001, ISO 14001 and ISO 50001 certified; standards on energy and resource consumption and other environmental practices have evolved positively over time. Cases B and C are ISO 9001 certified. These trends have not been reflected in the non-adopting utilities.

- Industrial partners. Utility B is owned by a private engineering company that is specialized in the water sector. This equity link provides the utility with technical expertise and innovative solutions. Utility $D$ is owned by a consortium of 200 textile firms, whose factories discharge into the public sewerage system. The utility was assigned the task of treating all the community effluents and of guaranteeing full compliance with the quality standards of the receiving environment. Utilities $\mathrm{D}$ and $\mathrm{F}$ are national leaders in their sector that continue to test cutting edge solutions obtained from specialized industrial providers. In all the studied cases, private ownership has also been associated with orientation toward operational efficiency, which may help drive innovation adoption. Utility $E$ draws sizeable technological and organizational expertise from one of its owners, namely a joint venture between an engineering firm and a private energy utility. Utility $A$ has expressed regret about the poor level of cooperation with the group's engineering firm, a possible sign of the utility's attention toward knowledge capital. No similar activism has been found in non-adopters.

- Experience. Most adopters benefit from learning economies, because they had been granted wastewater franchising contracts for several years at the observed time. Instead, 4 out of 5 non-adopters have only been managing the wastewater treatment service for 1 or 2 years.

- Size. Despite the economies of scale in innovation and slack managerial resources that are typical of larger utilities, the utility size is unlikely to explain AWWT adoption by itself. Horizontal fragmentation is observed for non-adopting cases $\mathrm{H}, \mathrm{I}, \mathrm{J}$ and $\mathrm{K}$, but adopting utilities $\mathrm{B}, \mathrm{D}$ and $\mathrm{F}$ only manage a small portion of the water district. Utility $\mathrm{B}$ has suggested that being

\footnotetext{
${ }^{8}$ Further interviews with the utilities staff could offer richer information about the role of EMSs capabilities. This has been left to future research.
} 
small is an advantage for municipally-owned utilities, because the obligation of introducing competitive tenders only comes into force after a given cost threshold has been exceeded. Public procurement rules might discourage the adoption of most advanced treatment systems, as utilities tend to award contracts to the lowest bids, in order to minimize the risk of appeals against the tender outcome.

\subsection{Firm-level determinants: Management professionalism}

The second firm-level determinant is a subtler factor that is harder to detect through interviews with utilities. In general terms, poor management professionalism is associated with weak corporate governance and patronage practices, which are more frequent in small municipallyowned utilities or inter-municipal joint ventures (Garrone et al. 2013; Garrone and Marzano 2014). Further insights have been collected through interviews with technology providers and local authorities.

- Interference from local governments. Adopting case A is a large municipally-owned utility. It reports that the local government limits itself to requiring civil works on water and wastewater grids in order to minimize the dwellers' complaints, but it does not interfere with investment decisions, which are driven by technical analyses, and the current and prospected environmental standards. Several hints on the intrusive and discretionary influence of local governments on investment planning have instead been collected for non-adopting utilities $G$ and $\mathrm{K}$. Utility $\mathrm{K}$ has explicitly claimed that the strong municipal influence has resulted in very low tariffs (unchanged since 2002), that is, in poor investment potential. Opportunistic practices have been observed in the shareholders' assembly, where mayors tend to oppose tariff increases, even though they are motivated by the adoption of AWWT technologies. The very high number of municipal owners makes investment approval very complex. Similar results have been reported, albeit less clearly, for non-adopting utilities $\mathrm{H}, \mathrm{I}$ and J.

- Weak corporate governance. Utilities B, D, E and F are owned by private industrial companies, and the interviewees in these companies have indicated that the recruitment and careers of their managers are in line with good corporate governance practices. Utility $A^{\prime}$ s corporate governance is strengthened by the publication of sustainability reports.

- Reactive attitude. Case $\mathrm{J}$ is a small inter-municipal consortium. A reactive approach, namely reaction to accidents or emergencies, has been reported to prevail; monitoring and modeling activities are virtually absent, and emerging issues are neither dealt with timely nor effectively 
(one manager claimed "it is time to replace the so-called 'hypothesis engineering' with 'data engineering', based on real time information").

In conclusion, as summarized in Table 5, adopters have developed and maintained technological and organizational capabilities to a high or medium degree. The same holds true for management professionalism. On the other hand, non-adopters lag behind in both dimensions, with the possible exception of non-adopter $\mathrm{G}$, which has resulted to be comparable with adopter $\mathrm{C}$.

\subsection{Community-level determinants}

The information on the attitude of the community members was mainly collected from secondary sources and third parties (Table 4) and a few cases of citizens' voice have been observed in the sample. Only the adoption of AWWT technologies in utilities D and F has been due to residents' pressure and complaints about wastewater treatment plants, namely about the release of colored wastewaters and the smell spreading from the plant. ${ }^{9}$

In both the $\mathrm{D}$ and $\mathrm{F}$ cases, the presence of water using industries has been found to outbalance any possible pressure from water polluting industries. In fact, both utilities are located in a city that hosts a textile district, but tourism and recreational activities are also well established locally, since the city is on a lake. Instead, a few other utilities are sited in areas where there is a concentration of firms releasing polluting effluents, without any significant presence of water using industries, i.e. cases $\mathrm{H}$ (textile, welding and metallurgy), I (metallurgy, galvanic plating, chemicals), utility J (metallurgy, tannery). These are all non-adopting utilities. In short, water polluting industries have been found to be present in both adopter and non-adopter service areas, but the discriminating factor toward adoption is constituted by the contemporaneous localization of water using industries in the focal areas.

Finally, Table 6 summarizes the key barriers to and drivers of the adoption of AWWT technologies.

\begin{tabular}{|l|c|c|}
\hline \multicolumn{1}{|c|}{ Conceptual framework } & Drivers & Barriers \\
\hline Industry-level determinants & Water quality standards & $\begin{array}{c}\text { Exposure to transaction costs } \\
\text { with local governments }\end{array}$ \\
\hline $\begin{array}{l}\text { Firm-level determinants - } \\
\text { Technological and } \\
\text { organizational capabilities }\end{array}$ & $\begin{array}{c}\text { Knowledge and know-how sourced from } \\
\text { research activities, EMS adoption, } \\
\text { industrial partnerships, learning } \\
\text { economies }\end{array}$ & $\begin{array}{c}\text { Lack of adequate knowledge } \\
\text { and know-how sources }\end{array}$ \\
\hline $\begin{array}{l}\text { Firm-level determinants - } \\
\text { Management professionalism }\end{array}$ & $\begin{array}{r}\text { Businesslike corporate governance } \\
\text { Sustainability reports }\end{array}$ & $\begin{array}{c}\text { Discretionary governance } \\
\text { Intrusive practices of local } \\
\text { politics }\end{array}$ \\
\hline
\end{tabular}

\footnotetext{
${ }^{9}$ In one case, a dwellers' committee exists that protests against the environmental impacts of the WWT plant nearby.
} 


\begin{tabular}{|l|c|c|}
\hline $\begin{array}{l}\text { Community-level } \\
\text { determinants }\end{array}$ & $\begin{array}{c}\text { Citizens' activism } \\
\text { Colocation of industries reliant on water } \\
\text { quality, e.g. recreational outdoor } \\
\text { services or food }\end{array}$ & $\begin{array}{c}\text { Colocation of water polluting } \\
\text { industries, e.g. textile, } \\
\text { metalworking or chemicals }\end{array}$ \\
\hline
\end{tabular}

Table 6. Summary of drivers and barriers to AWWT adoption

\section{Conclusion}

The present paper has investigated the adoption of water environmental innovations. The chosen setting, i.e. wastewater utilities, shares some critical characteristics with several other industries that are facing sizeable environmental challenges. The distinctive features are the high transaction costs, due to the specificity of the assets and exposure to the so-called "governmental opportunism", a complex and solid network of interests at the community-level, and an extreme variance in firm-level capabilities. The extant literature explored these characteristics marginally or as individual topics. After having developed a conceptual framework, aimed at identifying a set of firm- and community-level barriers to and drivers of AWWT technology adoption, descriptive case studies have been conducted on a sample of 11 water utilities operating in a region in North-Italy. Qualitative empirical evidence has been used to enrich and corroborate the theoretical predictions.

It has been found that, in a country where the regulation of the wastewater industry has traditionally not shielded the deployment of investments from transaction costs, the adoption of AWWT technologies is far from being universal, in spite of stringent water quality standards. Five out of the 11 sampled utilities did not adopt AWWT technologies and, thus, infringed European Council Directive 91/271/EEC. In this scenario, the search for common traits in the adoption cases has revealed a few factors that drive environmental technology adoption. Technological and organizational capabilities and management professionalism at firm-level are likely to positively moderate the water utility's decision to adopt AWWT technologies. Moreover, at communitylevel, the presence of citizens' voice and industries that are strongly reliant on a clean environment as a source of competitive advantage (e.g. tourism) are found to be likely enablers. On the other hand, there are stakeholders who feel that tariff increases following AWWT investments are a menace for their economic performance. The case studies have confirmed that the presence of water polluting industries (e.g. textile) leads to an increase in the possibility of not adopting. From the firm-level point of view, our results seem to suggest that technological and 
organizational capabilities and management professionalism of utilities may overcome the bottlenecks created by an adverse institutional environment, and spur wastewater utilities to adopt innovation. This evidence has relevant policy implications, with respect to both the restructuring of the wastewater market and the corporate governance of water utilities.

If a firm's capabilities play a key role in driving water innovation adoption, policy interventions should support those initiatives that strengthen knowledge transfer and know-how learning between the interested parties. Water alliances established to participate in research networks, to share good practices, to create synergies in view of the development of a "smart" agenda are valid examples in this domain. In addition, when any competition stimulus is absent, reputation effects, enabled by benchmarking regulations, could favor the adoption of AWWT. 10

Corporate governance should be the second pillar of the policy intervention directed toward water innovation adoption. On the one hand, the "one district-one provider" policy recently strengthened by Italian legislation may lead to improvements in this respect, since it can be expected that larger and better-endowed water utilities would also experience better-functioning corporate governance systems. On the other hand, additional and more targeted reforms are also welcome. Managerial professionalism, in fact, may be favored by the creation of water players that operate in a well-functioning regulatory framework, are under the scrutiny of financial markets, and undertake a process of reputation-building upon which top executives can lever on the market for managers. The search for managers and control practices that may work in a context of prevailing public ownership represents a critical challenge.

As far as the community-level is concerned, the paper shows that there are cities and territories whose residents and industries are able to either foster or slowdown the adoption of water innovations. While local governments are responsible for high-level planning and control activities, the independence of regulatory agencies that set tariffs and monitor the service and quality of water is critical to shield water utilities from the more myopic interests of politics and business. In other words, well-designed sector governance is a critical ingredient in the recipe to close the wastewater innovation gap.

Our analysis has been aimed at shedding new light on innovation dynamics in wastewater treatment technologies, by taking into account contextual specificities that can have a profound effect on the innovation decision. Environmental economics and management have so far paid

\footnotetext{
${ }^{10}$ The authors would like to thank an anonymous reviewer for offering this insight.
} 
limited attention to contexts in which innovation occurs in regulated industries and implies infrastructure deployment and a sunk investment. This work is a step in this investigation direction, even though much remains to be explored. For instance, community- and firm-level factors that have been found to affect the adoption of environmental technologies are likely to dynamically co-evolve over time; the resulting mutual relationships are worthy of study. ${ }^{11}$ Moreover, the individuation of other relevant firm-level and community-level factors could be an interesting addition to the present study.

Finally, the independence of water regulators is necessary to insulate investment and innovation decisions from those instances of local politics and business that depress the incentives and capabilities of investing. This has been a positive hallmark of the Italian scenario since 2012, and of other water and wastewater industries for even longer. However, this study warns against possible inconsistency between environmental policies and national and local sector regulations (EIP 2014; Wehn and Montalvo 2014). What mechanisms can rule out this inconsistency? At a more general level, what links between sector and environmental policymakers can be put in place to sustain knowledge transfer and mutual adaptation? These questions have been left open in our analysis, but we believe that they deserve careful consideration by scholars and policymakers concerned with environmental innovation in water and wastewater sectors.

\section{Acknowledgments}

This work has been supported by HIL - the Hydrolnformatics Lab of Politecnico di Milano (WINTES grant). We would like to thank Roberto Canziani for extremely helpful discussions, and the editors and three anonymous reviewers for their useful comments. The responsibility for errors and opinions remains ours.

\section{References}

AEEGSI (Autorità per l'Energia il Gas il Sistema Idrico), 2012. Consultazione Pubblica per l'Adozione di Provvedimenti Tariffari in Materia di Servizi Idrici, DCO 204/2012/R/IDR.

Berrone, P., Fosfuri, A., Gelabert, L., Gomez-Mejia, L. R., 2013. Necessity as the mother of "green" inventions: Institutional pressures and environmental innovations. Strategic Management Journal 34(8), 891-909. doi:10.1002/smj

\footnotetext{
${ }^{11}$ The authors would like to thank an anonymous reviewer for suggesting this future research effort.
} 
Bloom, N., Genakos, C., Martin, R., Sadun, R., 2010. Modern Management: Good for the Environment or Just Hot Air?*. The Economic Journal 120(544), 551-572.

Boons, F., Montalvo, C., Quist, J., \& Wagner, M., 2013. Sustainable innovation, business models and economic performance: an overview. Journal of Cleaner Production, 45, 1-8.

Buysse, K., Verbeke, A., 2003. Proactive Environmental Strategies: A Stakeholder Management Perspective. Strategic Management Journal 24(5), 453-470.

Chang, S.J., van Witteloostuijn, A, Eden, L., 2010. From the Editors: Common method variance in international business research. Journal of International Business Studies 41, 178-184.

Delmas, M., Russo, M.V., Montes-Sancho, M.J., 2007. Deregulation and environmental differentiation in the electric utility industry. Strategic Management Journal 28(2), 189-209.

EC (European Commission), 2013a. A Water Blueprint for Europe. Publications Office of the European Union, Luxembourg.

EC (European Commission), 2013b. Seventh Report on the Implementation of the Urban Waste Water Treatment Directive (91/271/EEC), Brussels. Available online at http://eurlex.europa.eu/legal-content/EN/TXT/PDF/?uri=CELEX:52013DC0574\&from=EN

EIP Water (European Innovation Partnership on Water), 2014. Barriers and bottlenecks for Innovation in the Water Sector. 1st Stage: Identification of non-technological barriers and definition of priority and intervention measures. Final Report, including comments from the Steering Group, European Commission, DG Environment.

Federutility, 2014. I servizi idrici in Italia. Presentation available online at http://www.industriaenergia.it/wp-content/uploads/2014/04/4.Claudio-COSENTINO-

Federutility.pdf (in Italian).

Ford, J.A., Steen, J., Verreynne, M.L., 2014. How environmental regulations affect innovation in the Australian oil and gas industry: going beyond the Porter Hypothesis. Journal of Cleaner Production 84, 204-213.

Fuenfschilling, L., Truffer, B., 2014. The structuration of socio-technical regimes-Conceptual foundations from institutional theory. Research Policy 43, 772-791.

Garrone P., Grilli L., Rousseau, X., 2013. Management Discretion and Political Interference in Municipal Enterprises. Evidence from Italian Utilities. Local Government Studies 39 (4), 514-540

Garrone P., Marzano R., 2014. Why do local governments resist contracting out? Urban Affairs Review, doi:1078087414549548.

Geroski, P.A., 2000. Models of technology diffusion. Research policy 29(4), 603-625.

Goldberg, V.P., 1976. Regulation and administered contracts. The Bell Journal of Economics 7(2), 426-448.

Harvey, B., Schaefer, A., 2001. Managing relationships with environmental stakeholders: A study of UK water and electricity utilities. Journal of Business Ethics 30, 243-260.

ISTAT (Istituto Nazionale di Statistica), 2014. Censimento delle acque per uso civile. Anno 2012. Roma. Available online at http://www.istat.it/it/archivio/127380 (in Italian).

ISTAT (Istituto Nazionale di Statistica), 2015. Giornata mondiale dell'acqua. Le statistiche dell'Istat. Roma. Available online at http://www.istat.it/it/archivio/153580 (in Italian). 
Karshenas, M., Stoneman, P., 1993. Rank, stock, order and epidemic effects in the diffusion of new process technologies. Rand Journal of Economics 24, 503-528.

Kassinis, G., Vafeas, N., 2006. Stakeholder pressures and environmental performance. Academy of Management Journal 49(1), 145-159.

Kemp, R., Volpi, M., 2008. The diffusion of clean technologies: a review with suggestions for future diffusion analysis. Journal of Cleaner Production 16(1), S14-S21.

Khanna, M., Damon, L. A., 1999. EPA's Voluntary 33 / 50 Program: Impact on Toxic Releases and Economic Performance of Firms. Journal of Environmental Economics and Management 37(1), 125.

Krozer, Y., Hophmayer-Tokich, S., van Meerendonk, H., Tijsma, S., Vos, E., 2010. Innovations in the water chain-experiences in The Netherlands. Journal of Cleaner Production 18(5), 439-446.

Lopez, F. J. D., \& Montalvo, C. (2015). A comprehensive review of the evolving and cumulative nature of eco-innovation in the chemical industry. Journal of Cleaner Production, 102, 30-43.

Levy, B., Spiller, P., 1994. Institutional Foundations of Regulatory Commitment: A Comparative Analysis of Telecommunications Regulation. The Journal of Law, Economics, \& Organization 10(2), 201-246.

Luken, R., Van Rompaey, F., 2008. Drivers for and barriers to environmentally sound technology adoption by manufacturing plants in nine developing countries. Journal of Cleaner Production 16(1), S67-S77.

Martin, R., Muûls, M., de Preux, L.B., Wagner, U.J., 2012. Anatomy of a paradox: Management practices, organizational structure and energy efficiency. Journal of Environmental Economics and Management 63(2), 208-223.

Mitchell, R.K., Angle, B.R., \& Wood, D.J.,1997. Toward a theory of stakeholder identification and salience: Defining the principle of who and what really counts. Academy of Management Review, 22(4), 853-886.

Mollinga, P.P., 2008. Water, politics and development: Framing a political sociology of water resources management. Water Alternatives 1(1): 7-23.

Montalvo, C., 2008. General wisdom concerning the factors affecting the adoption of cleaner technologies: a survey 1990-2007. Journal of Cleaner Production 16(1), S7-S13.

OECD (Organisation for Economic Co-operation and Development), 2011a. Benefits of Investing in Water and Sanitation: An OECD Perspective, OECD Studies on Water. OECD Publishing, Paris.

OECD (Organisation for Economic Co-operation and Development), 2011b. Invention and transfer of environmental technologies, OECD Studies on Environmental Innovation. OECD Publishing, Paris.

OECD (Organisation for Economic Co-operation and Development), 2012. OECD Environmental Outlook to 2050 and the Consequences of Inaction, Chapter 5: Water. OECD Publishing, Paris.

OECD (Organisation for Economic Co-operation and Development), 2013. Environment at a Glance 2013: OECD Indicators. OECD Publishing, Paris. http://dx.doi.org/10.1787/9789264185715-en

Romano, G., Guerrini, A., Campedelli, B., 2015. The new Italian water tariff method: A launching point for novel infrastructures or a backwards step? Utilities Policy 34, 45-53. 
Spiller, P., 1993. Institutions and regulatory commitment in utilities' privatization. Industrial and Corporate Change 2(1), 387-450.

Spiller, P., Savedoff, W., 1999. Government opportunism and the provision of water. (Savedoff, W. and Spiller, P. T. eds.). Spilled Water: An Institutional Commitment to the Provision of Water Services, Washington, DC: InterAmerican Development Bank, 1-34.

Spiller, P., 2013. Transaction cost regulation. Journal of Economic Behavior \& Organization 89, 232-242.

Veugelers, R., 2012. Which policy instruments to induce clean innovating? Research Policy 41(10), 1770-1778.

Wagner, M., 2008. Empirical influence of environmental management on innovation: Evidence from Europe. Ecological Economics 66, 392-402.

Wehn, U., Montalvo, C., 2014. Exploring the dynamics of water innovation. Journal of Cleaner Production 30, 1-4.

Williamson, O.E., 1976. Franchise bidding for natural monopolies in general and with respect to CATV. The Bell Journal of Economics 7(1), 73-104. 